\title{
Comparative study of the skin pathergy test with blunt and sharp needles in Behçet's disease: confirmed specificity but decreased sensitivity with sharp needles
}

\author{
Nihat Dilşen, Meral Koniçe, Orhan Aral, Lale Öcal, Murat İnanç, Ahmet Gül
}

\begin{abstract}
Objective-To compare the specificity and sensitivity of the skin pathergy test performed with blunt and sharp needles in patients with Behçet's disease.

Methods-The skin pathergy test was performed using the simultaneous four needle prick method with blunt and sharp, thick and thin needles in 92 patients with Behçet's disease, 64 healthy controls, and 128 patients without Behçet's disease. The test was evaluated at 48 hours.

Results-No positive skin pathergy test was found in healthy controls and patients without Behçet's disease. The frequency and intensity of the positive skin pathergy test with blunt needles were significantly higher than those with sharp needles. Conclusion-This study reconfirmed the specificity of a positive skin pathergy test for Behçet's disease using blunt and sharp needles and showed a decreased sensitivity and intensity of the reaction with sharp needles.
\end{abstract}

(Ann Rheum Dis 1993; 52: 823-825)

Behçet's disease, which was first described by Behçet, a Turkish dermatologist, in $1937,{ }^{1}$ is a multisystemic inflammatory disorder characterised mainly by vasculitis. The skin pathergy test (non-specific skin hyperreactivity, needle prick test), first reported by Blobner, ${ }^{2}$ is the skin hyperreactivity associated with erythema, papules or pustules which is induced by intradermal prick in some patients with Behçet's disease. In most studies the skin pathergy test has been performed using either an intradermal injection of physiological saline or a sterile needle prick, or both, without reporting the size and sharpness of the needles. ${ }^{34}$ The simultaneous application of multiple needles is rarely used. ${ }^{45}$ Many investigators read the skin pathergy test at either 24 or 48 hours and evaluated the test as positive by taking into account the formation of erythematous papules or pustules at the prick site, whereas others considered only the erythema or papule. ${ }^{4} 6$ The test was assessed semiquantitatively from zero to $3+$ by some workers. ${ }^{578}$ As we had noticed some methodological discrepancies in the reports of the test and had also had some difficulties in the standardisation and evaluation of the test we carried out a prospective study to standardise and evaluate the skin pathergy test in healthy controls, patients without Behçet's disease, and in patients with Behçet's disease. ${ }^{9}$ That study showed the high specificity and high sensitivity of the test in Behçet's disease and therefore we included the positive skin pathergy test in our diagnostic criteria as a separate criterion. ${ }^{10}$

We noticed that the frequency of a positive skin pathergy test in our patients with Behçet's disease decreased markedly after the introduction of disposable needles in Turkey in 1986. We thought that the higher sensitivity of the skin pathergy test in our previous study might have been due to the use of the nondisposable, resterilised blunt needles. For this reason we have conducted a prospective study to compare the prevalance of a positive skin pathergy test by using sharp and blunt needles in our patients with Behçet's disease and the preliminary results were reported in $1990 .{ }^{11}$ The purpose of this paper is to present the results of the completed study.

\section{Patients and methods}

The skin pathergy test was performed in 92 patients with Behçet's disease fulfilling our criteria $^{10}$ and those of the International Study Group. ${ }^{12}$ The demographic features of patients with Behçet's disease were as follows: number of men, 51; number of women, 41 ; mean age, 33.2 years (range 16-59); mean age at onset, 25.4 years (range 19-51); and mean duration of Behçet's disease, 8.5 years (range three months to 32 years). The test was also performed in 64 sex and age matched healthy controls and 128 patients without Behçet's disease (29 with rheumatoid arthritis, five with ankylosing spondylitis, 11 with systemic lupus erythematosus, four with progressive systemic sclerosis, two with dermatomyositis/poly- \\ Istanbul Medical \\ Faculty, Department \\ Division of \\ Istanbul, Turkey \\ 13 July 1993
}


Table 1 Results of a skin pathergy test in 92 patients with Behcet's disease. Results given as No (\%) of subjects

\begin{tabular}{|c|c|c|c|c|c|c|c|c|}
\hline \multirow[t]{2}{*}{$S P T$} & \multicolumn{4}{|c|}{ Blunt needles } & \multicolumn{4}{|c|}{ Sharp needles } \\
\hline & $I V_{l}$ & $S C_{1}$ & $P S_{18}$ & $S C_{18}$ & $I V_{1}$ & $S C_{1}$ & $P S_{18}$ & $S C_{18}$ \\
\hline $\begin{array}{l}\text { Negative } \\
\text { Suspect }\end{array}$ & $\begin{array}{l}41(45) \\
10(11)\end{array}$ & $\begin{array}{l}31(34) \\
17(19)\end{array}$ & $\begin{array}{c}70(76) \\
5(5)\end{array}$ & $\begin{array}{l}34(37) \\
17(19)\end{array}$ & $\begin{array}{c}67(73) \\
7(8)\end{array}$ & $\begin{array}{l}72(78) \\
10(11)\end{array}$ & $\begin{array}{c}75(82) \\
5(5)\end{array}$ & $\begin{aligned} 77 & (84) \\
5 & (5)\end{aligned}$ \\
\hline Positive & $41(45)^{a}$ & $44(48)^{b}$ & $17(19)^{c}$ & $41(45)^{d}$ & $18(20)$ & $10(11)$ & $12(13)$ & $10(11)$ \\
\hline
\end{tabular}

a $v \mathrm{e}, \mathrm{p}<0.01 ; \mathrm{b} v \mathrm{f}, \mathrm{p}<0.001, \mathrm{c} v \mathrm{~g}, \mathrm{p}>0.05 ; \mathrm{d} v \mathrm{~h}, \mathrm{p}<0.001$.

Abbreviations: SPT $=$ skin pathergy test; $I_{1}=$ intravenous prick with No 1 needle; $\mathrm{SC}_{1}=$ subcutaneous prick with No 1 needle;

$\mathrm{PS}_{18}=$ physiological saline injection into the skin with No 18 needle; $\mathrm{SC}_{18}=$ subcutaneous prick with No 18 needle.

^As suspect reactions with sharp needles are specific for Behcet's disease, we compared the positive results with blunt needles with the sum of positive and suspect results with sharp needles (that is, $\mathrm{e}=25(28 \%) ; \mathrm{f}=20(22 \%), \mathrm{g}=17(18 \%), \mathrm{h}=15(16 \%))$.

myositis, six with vasculitis, 30 with ulcerative colitis, two with Crohn's disease, six with familial Mediterranean fever, seven with various haematological disorders, 14 with various malignancies, and 12 others).

For the skin pathergy test we used the simultaneous four needle prick method with blunt (used, resterilised) and sharp (unused, disposable) hypodermic needles of two sizes: $20 \mathrm{G}=$ No $1,26 \mathrm{G}=$ No 18 . After cleaning with alcohol, venepuncture was performed with a $20 \mathrm{G}$ needle $\left(\mathrm{IV}_{1}\right)$, two subcutaneous pricks with $20 \mathrm{G}\left(\mathrm{SC}_{1}\right)$ and $26 \mathrm{G}\left(\mathrm{SC}_{18}\right)$ needles (at least $3 \mathrm{~mm}$ deep), and one intracutaneous injection of $0.1 \mathrm{ml}$ physiological saline with a $26 \mathrm{G}$ needle $\left(\mathrm{PS}_{18}\right)$. The test was applied to a hairless avascular area of the skin on the flexor aspect of the forearm and the needles were inserted obliquely without rotation almost two centimetres apart on the midline by one of two trained laboratory technicians. The blunt and sharp needles were applied separately to each arm. As we had found the test to be positive at 24 but not at 48 hours in some of the healthy controls and patients without Behçet's disease in our previous study, and we had also observed the same results with sharp needles since that study, each test was only read at 48 hours by two researchers blindly according to our previous guide. ${ }^{9}$ The test was evaluated as an agreed result of the two observers as negative, suspect, or positive (from $1+$ to $4+$ ). For statistical purposes we scored the intensity of the reaction as zero for negative, 0.5 for suspect, and 1-4 for 1+ to 4+ respectively.

For the statistical analysis, Student's $t$ test, the paired $t$ test, and the $\chi^{2}$ test were used.

\section{Results}

The results of the skin pathergy test in healthy controls and patients without Behçet's disease were similar. No positive skin pathergy test was found with the sharp or blunt needles. The suspect reaction was not observed with the sharp needles, although it was observed with the blunt needles using the $\mathrm{IV}_{1}$ and $\mathrm{SC}_{1}$ methods ( 5 and $6 \%$ of subjects respectively) in healthy controls, and by the $\mathrm{IV}_{1}$ and $\mathrm{SC}_{1}$ methods in $2 \%$ of the patients without Behçet's disease. Table 1 gives the skin pathergy test results in 92 patients with Behçet's disease. As we observed suspect reactions in patients with Behçet's disease, patients without Behçet's disease, and healthy controls with blunt needles, and only in patients with Behçet's disease with sharp needles, a suspect reaction with sharp needles was accepted as 'positive'
Table 2 Mean (SD) intensity scores of positive skin pathergy test with four different methods

\begin{tabular}{llll}
\hline Methods $^{\star}$ & \multicolumn{2}{l}{ Type of needle } & \multirow{2}{*}{ p Value } \\
\cline { 2 - 3 } & Blunt & Sharp & \\
\hline IV $_{1}$ & $1.29(1.35)$ & $0.42(0.94)$ & $<0.001$ \\
SC $_{1}$ & $1.33(1.27)$ & $0.42(1.01)$ & $<0.001$ \\
PS $_{18}$ & $0.61(1.13)$ & $0.18(0.49)$ & $<0.001$ \\
SC $_{18}$ & $1.19(1.27)$ & $0.18(0.50)$ & $<0.001$ \\
\hline
\end{tabular}

Blunt $v$ sharp needles by each method, $\mathrm{p}<0.001 ; \mathrm{SC}_{1}$ (blunt) $v \mathrm{SC}_{18}$ (blunt), $\mathrm{p}>0.05 ; \mathrm{SC}_{1}$ (sharp) $v \mathrm{SC}_{18}$ (sharp), $\mathrm{p}=0.051$. prick with No 1 needle; $\mathrm{PS}_{18}=$ physiological saline injection into the skin with No 18 needle; $\mathrm{SC}_{18}=$ subcutaneous prick with No 18 needle.

and specific for Behçet's disease. Therefore we compared the positive skin pathergy test results with blunt needles with the sum of the suspect and positive results with sharp needles. The frequencies of the skin pathergy test by the $\mathrm{IV}_{1}$, $\mathrm{SC}_{1}$, and $\mathrm{SC}_{18}$ methods using blunt needles were significantly higher than those with sharp needles. The frequency of the positive skin pathergy test with blunt needles ranged from 19 to $48 \%$, whereas this ranged from 16 to $27 \%$ with the sharp needles.

Table 2 gives the mean intensity scores of the reaction by the four methods. The scores of the reaction with blunt needles were significantly higher than those with sharp needles at each prick site $(p<0.001)$. By using sharp needles the mean intensity scores of the reaction by the $\mathrm{IV}_{1}$ and $\mathrm{SC}_{1}$ methods were similar and higher than those with the $\mathrm{PS}_{18}$ and $\mathrm{SC}_{18}$ methods. Comparing the results of the $\mathrm{SC}_{1}$ and $\mathrm{SC}_{18}$ methods (using needles of different thickness by the same route), the blunt and thick needles caused more intense reactions than the sharp, thinner needles $(p=0.051)$.

\section{Discussion}

Different aspects of the skin pathergy test have been studied by many workers since 1937 and it is accepted as an important tool in the diagnosis of Behçet's disease. Although some workers found the test to be positive in all of their patients, the prevalence of a positive skin pathergy test in Behçet's disease varies between countries and from one investigator to another (for example, by more than $60 \%$ in Turkey, Iran, and Tunisia, and less than $20 \%$ in the United Kingdom and USA). ${ }^{367912}$ The skin pathergy test was negative in a small number of healthy subjects in two studies. ${ }^{6}{ }^{13}$ In some studies a few patients without Behçet's disease were reported to have positive reactions, but it is not known whether or not they later developed Behçet's disease. ${ }^{6} 1415$ 
Our previous study of the skin pathergy test using the same method as the present study but using only blunt needles in 152 patients with Behçet's disease, 240 patients without Behçet's disease, and 122 healthy controls showed the following important features: the frequency of a positive skin pathergy response was $67 \%$ with $\mathrm{SC}_{1}, 63 \%$ with $\mathrm{IV}_{1}, 60 \%$ with $\mathrm{SC}_{18}$, and $40 \%$ with $\mathrm{PS}_{18}$; the intensities of the reactions at the four prick sites were not homogeneous in almost half of the patients with Behçet's disease; even over short time periods the test could change from positive to negative and rarely from negative to positive; with a few exceptions a positive skin pathergy test did not correlate well with the various demographic and some clinical features; although some of the healthy controls and patients without Behçet's disease had a positive skin pathergy test at 24 hours, none had a positive reaction at 48 hours; our previous study of the skin pathergy test in the relatives of 48 probands showed that a positive skin pathergy test was observed in some of the first degree healthy relatives of the probands ${ }^{16}$; and considering the high specificity and high sensitivity of the pathergy phenomenon in Behçet's disease, we included a positive skin pathergy test in our set of diagnostic criteria as a 'specific criterion'. ${ }^{10}$

Our present study, in which blunt and sharp needles were used simultaneously for the skin pathergy test, not only confirmed some of these results of our previous study but also emphasised further features of the pathergy phenomenon. We could not find any positive skin pathergy test in healthy controls and patients without Behçet's disease, and therefore the high specificity of the test was confirmed once more. A significant decrease in the sensitivity and intensity of the skin pathergy test with sharp needles was observed; as even small papules with erythema (the so called 'suspect reaction' in our previous study) with sharp needles was seen in patients with Behçet's disease but not in the controls, it was accepted as a positive reaction. As a significant influence of the sharpness of the needles on the intensity of the pathergy reaction was observed, we modified our previous grading definitions accordingly (table 3$)^{9}$

The use of blunt needles before 1986 in Turkey may explain the higher prevalence of a positive pathergy test in the past. This has also

Table 3 Grading and definitions of skin pathergy test

\begin{tabular}{lll}
\hline Grades of $S P T^{*}$ & \multicolumn{2}{l}{ Characteristics of the pathergy reaction at 48 hours } \\
\cline { 2 - 3 } & Blunt needles & Sharp needles \\
\hline Negative $(-)$ & Only erythema or trace of prick & Only erythema or trace of prick \\
Suspect $( \pm)$ & Papule $<2 \mathrm{~mm}+$ erythema & \\
Positive $(+)$ & Papule $2-3 \mathrm{~mm}+$ erythema & Papule $\leqslant 3 \mathrm{~mm}+$ erythema \\
$1+$ & Papule $>3 \mathrm{~mm}+$ erythema & Papule $>3 \mathrm{~mm}+$ erythema \\
$2+$ & Pustule $1-2 \mathrm{~mm}$ & Pustule $1-2 \mathrm{~mm}$ \\
$3+$ & Pustule $>2 \mathrm{~mm}$ & Pustule $>2 \mathrm{~mm}$ \\
$4+$ & & \\
\hline
\end{tabular}

${ }^{\star} \mathrm{SPT}=$ Skin pathergy test. been suggested by another group in Turkey. ${ }^{17}$ The same problem may occur in other developing countries (for example, Iran, Tunisia, Morocco, and Algeria). Furthermore, the lower prevalence of the skin pathergy test in developed countries might also be related to the long term use of disposable needles.

In conclusion, a positive skin pathergy test at 48 hours is specific for Behçet's disease. Positive reactions are more common and intense with blunt needles than with sharp needles. We suggest that two or more simultaneous subcutaneous pricks with thick needles (e.g. $20 \mathrm{G}=$ No 1 ) should be used for the skin pathergy test and we suggest that if standardised blunt needles can be made, the sensitivity of the test will be increased further.

The authors are grateful to Miss Ömür Aksakallı and Miss Besra Duruk for their technical assistance in performing the skin pathergy test and to Mr Recep Ertaş for his secretarial help.

1 Behçet $H$. Über rezidivierende aphtöse, durch ein Virus verursachte Geschwüre am Mund, am Auge und an den Genitalien. Dermatol Wochenschr 1937; 105: 1152-7.

2 Blobner F. Zur rezidivierenden Hypopyon-iritis. $Z$ Augenheik 1937; 91: 129-39.

3 Hubault A, Hamza M. La Maladie de Behçet en 1974. $L$ 'actualite rhumatologique. Paris: Expansion Scientifique, 1974: 43-55.

4 Suzuki K, Mizuno N. Intracutaneous test with physiologica saline in Behçet's disease. In: Inaba G, ed. Behçet's disease, pathogenetic mechanism and clinical feature. Tokyo University of Tokyo Press, 1982: 333-42.

5 Sobel J D, Haim S, Shafrir A, Gellei B. Cutaneous hyperreactivity in Behçet's disease. Dermatologica 1973; 146: $350-6$

6 Tüzün Y, Yazıcı H, Pazarlı B, Yalçın S, Yurdakul S, Müftüoğlu A. The usefulness of the nonspecific skin hyperreactivity (the pathergy test) in Behçet's disease in hyperreactivity (the pathergy test) in Behçet's disease
Turkey. Acta Derm Venereol (Stockh) 1978; 59: 77-9.

7 Nazzaro P. Cutaneous manifestations of Behçet's disease clinical and histopathological findings. In: Monacelli $M$ Nazzaro P, eds. Behçet's Disease. Basle, New York: Karger, 1966: 15-21.

8 Yazıcı $\mathrm{H}$, Chamberlain $M$ A, Tüzün $Y$, Yurdakul S, Müftüoğlu A. A comparative study of the pathergy reaction among Turkish and British patients with Behçet's disease. Ann Rheum Dis 1984; 43: 74-5.

9 Dilşen N, Koniçe M, Aral O, Aykut S. Standardization and evaluation of the skin pathergy test in Behçet's disease and controls. In: Lehner T, Barnes C G, eds. Recent advances in Behfet's disease. London: Royal Society of Medicine in Behçet's disease. Lond

10 Dilşen N, Koniçe M, Aral O. Our diganostic criteria of Behçet's disease-an overview. In: Lehner T, Barnes $C$ $\mathrm{G}$. Recent advances in Behçet's disease. London: Royal Society of Medicine Services, 1986; 177-80.

11 Dilşen N, Koniçe M, Aral O, Ocal L. How can we increase the sensitivity of the skin pathergy test in Behcet's disease. In: V Congreso de Reumatologia des Los Paises Mediterraneos resumenes. Madrid; 15-17 October 1990. 1990: 226.

12 International Study Group. Evaluation of diagnostic (classification) criteria in Behçet's disease: towards (classification) criteria in Behçet's disease: towards internationall $299-308$.

13 Davies P G, Fordham J N, Kirwan J R, Barnes C G, Dinning W J. The pathergy test and Behçet's syndrome in Britain. Ann Rheum Dis 1984; 43: 70-3.

14 Shimuzu T. Clinicopathological studies on Behçet's disease. In: Dilsen N, Konice M. Ovül C, eds. Behcet's Disease. Proceedings of an International Symposium on Behcet's Disease (Istanbul, 1977). Amsterdam, Oxford: Excerpta Medica, 1979: 9-43.

15 Mizoguchi M, Chikakane K, Goh K, Asahina Y, Masuda K. Acute febrile neutrophilic dermatosis (Sweet's syndrome) in Behçet's disease. Br $\mathcal{F}$ Dermatol 1987; 116: syndrome)

16 Aral O, Dilşen N, Koniçe M. Positive skin pathergy reactivity as a genetic marker of Behcet's disease. In Lehner T, Barnes C G, eds. Recent advances in Behcet's disease. London: Royal Society of Medicine Services, 1986: 173-5.

17 Özarmağan G, Saylan T, Azizlerli G, Övül C, Aksungur V L. Re-evaluation of the pathergy test in Behçet's disease. Acta Derm Venereol (Stockh) 1991; 71: 75-6. 